\title{
Pengaruh ROA, Pertumbuhan Penjualan, Likuiditas dan Ukuran Perusahaan terhadap Struktur Modal Perusahaan Manufaktur Sektor Makanan dan Minuman di BEI
}

\author{
Metyria Imelda Hutabarat \\ STIE ITMI \\ metyriaimelda@gmail.com
}

\begin{abstract}
Food and beverage companies are industries that compete in the world market and make major contribution to the value of national exports. Companies that have good capital structure have a good reputation and affect the high stock price. This research aimed to find out the effect of ROA, sales growth, liquidity, company size variable to capital structure variable in annual report listed on the Indonesia Stock Exchange year 2017-2019. The population are all food and beverage manufacturing companies listed on the Indonesia Stock Exchange, and obtained samples of amount 14 companies. The type of this research is a quantitative study. The data analysis used several analyzes, namely multiple linear analysis, the coefficient of determination test, the classical assumption test, $R 2$ test, the F test, and the $t$ test. Based on the results of this research, that partially profitability has significant positive effect on capital structure. Sales growth has no significant negative effect on capital structure. Liquidity has no significant negative effect on capital structure. Company size variable has significant positive effect on capital structure. The results of $F$ test show that profitability, sales growth, liquidity, company size have significant positive effect on capital structure.
\end{abstract}

Keywords: ROA, sales growth, liquidity, company size, DER

\section{PENDAHULUAN}

Perusahaan makanan dengan minuman telah siap mengikuti kemajuan revolusi perkembangan teknologi industri 4.0 di Indonesia yang bersaing di pasar dunia, kenaikan lapangan untuk tenaga kerja dan telah berpartisipasi sangat andil untuk ekspor. Penerapan kompetensi digital diperkirakan akan memberikan dampak dan berpengaruh kuat, baik serta yang akan mendatangkan akibat yang positif untuk memiliki nilai investasi perusahaan yang berkembang. Mampunya perusahaan makanan dengan minuman dalam mewujudkan para tenaga kerja berkualifikasi untuk mengikuti pesatnya perkembangan zaman kecanggihan teknologi digital dan mewujudkan pertumbuhan ekonomi secara khusus di bidang industri akan memberikan sumbangsih untuk kemajuan keuangan Indonesia.

Perusahaan makanan dan minuman merupakan perusahaan nasional go public bertujuan memperoleh keuntungan (profitabilitas). Untuk mencapai profitabilitas diperlukan keputusan penting dalam variabel struktur modal keuangan perusahaan. Struktur modal dapat diartikan sebagai bauran terbaik banyaknya komposisi hutang serta ekuitas untuk mendanai perusahaan yang mendukung kegiatan operasionalisasi maupun investasi perusahaan. Perseroan yang mempunyai struktur modal tinggi akan menyandang nama baik sehingga tingginya saham sesuai keinginan para pemegang saham.

Profitabilitas adalah kemampuan perusahaan dalam menghasilkan laba. Profitabilitas merupakan standar kemampuan perusahaan untuk mencatat laba dalam suatu periode. (Kharizmatullah, Yuliani \& Ghasarma, 2017). Profitabilitas menjadi tingkat keberhasilan perusahaan dalam mencapai keuntungan dalam suatu kurun waktu. Menurut (Andika \& Sedana, 2019) profitabilitas penelitian dihitung menggunakan ROA yang dapat menunjukkan pengembalian investasi yang dimiliki perusahaan dalam semua asetnya. Perseroan yang jumlah ROA besar umumnya akan menghasilkan keuntungan yang besar juga sehingga mempunyai kas perusahaan yang besar sedangkan keperluan dari dana eksternal menurun. 
Pertumbuhan penjualan merupakan gambaran pendapatan yang menentukan kesinambungan keberlangsungan hidup perusahaan. Manajemen perusahaan akan tetap berusaha menambah peningkatan laju penjualan produk karena pertumbuhan penjualan yang tinggi cendrung meningkatkan laba perusahaan. Perusahaan yang memiliki pertumbuhan penjualan yang selalu bertumbuh mengakibatkan struktur modalpun meningkat.

Likuiditas (current ratio) menunjukkan kemampuan suatu perusahaan memenuhi liabilitas jangka pendek. Perusahaan dapat memenuhi kewajiban jangka pendek diakui likuid sebaliknya apabila tidak mampu dinyatakan illikuid (Zulkarnain, 2020). Current ratio digunakan sebagai suatu rasio untuk menunjukkan tingkatan manajemen dalam memenuhi utang lancar sewaktu pembayaran. Perusahaan dalam kemampuannya dapat tetap beroperasional dengan baik meskipun diharuskan membayar kewajiban yang membuat dana operasional berkurang (Farisa \& Widati, 2017). Perusahaan yang liquiditynya besar dapat dianggap mempunyai total aset lancar yang banyak dibanding total utang lancar. Perseroan mempunyai sendiri jumlah dana internal yang besar dalam melunasi hutang atau kewajibannya.

Ukuran perusahaan merupakan rasio dalam menunjukkan kecil atau besarnya suatu perusahaan. Perusahaan dianggap besar disebabkan mempunyai total aset besar, cendrung memiliki reputasi yang cukup baik di mata masyarakat maka tambahan biaya tidak diperlukan untuk penyediaan atau pengadaan modal. Menurut (Andika \& Sedana, 2019) perusahaan besar umumnya tidak sulit mendapatkan pinjaman berbanding terbalik dengan perusahaan kecil. Ukuran perusahaan yang semakin besar akan membuat bertambah mudahnya suatu perusahaan memperoleh modal eksternal untuk kapasitas utang yang banyak.

\section{Rumusan Masalah}

Berdasarkan latar belakang penelitian, dapat dibuat rumusan masalah penelitian yaitu bagaimana profitabilitas mempengaruhi DER, hubungan antara pertumbuhan penjualan pada DER, bagaimana hubungan antara CR pada DER, hubungan antara ukuran pada DER.

\section{STUDI LITERATUR}

Tabel 1. Penelitian Terdahulu

\begin{tabular}{|c|c|c|c|}
\hline Peneliti (Tahun) & Judul Penelitian & Metode Analisis & Kesimpulan \\
\hline $\begin{array}{l}\text { (Lilia, } \\
\text { Situmeang, } \\
\text { Verawaty, \& } \\
\text { Hartanto, 2020) }\end{array}$ & $\begin{array}{l}\text { Pengaruh } \\
\text { Profitabilitas, } \\
\text { Likuiditas, Ukuran } \\
\text { Perusahaan } \\
\text { terhadap Struktur } \\
\text { Modal Perusahaan } \\
\text { Property dan Real } \\
\text { Estate yang } \\
\text { terdaftar di BEI }\end{array}$ & $\begin{array}{l}\mathrm{X}_{1}: \text { Profitabilitas } \\
\mathrm{X}_{2}: \text { Likuiditas } \\
\mathrm{X}_{3}: \text { Ukuran Perusahaan } \\
\text { Y: Struktur Modal }\end{array}$ & $\begin{array}{l}\text { Profitabilitas dan } \text { likuiditas } \\
\text { pengaruh negatif, tidak } \\
\text { signifikan terhadap struktur } \\
\text { modal. Ukuran perusahaan } \\
\text { pengaruhnya positif dan } \\
\text { signifikan terhadap struktur } \\
\text { modal }\end{array}$ \\
\hline $\begin{array}{l}\text { Komariah \& } \\
\text { Nurulrahmatiah, } \\
(2020)\end{array}$ & $\begin{array}{l}\text { Pengaruh Struktur } \\
\text { Aktiva dan } \\
\text { Likuiditas terhadap } \\
\text { Struktur Modal } \\
\end{array}$ & $\begin{array}{l}\mathrm{X}_{1}: \text { Struktur Aktiva } \\
\mathrm{X}_{2}: \text { Likuiditas } \\
\text { Y: Struktur Modal }\end{array}$ & $\begin{array}{l}\text { Struktur aktiva pengaruh } \\
\text { signifikan pada struktur modal, } \\
\text { likuiditas tidak pengaruh } \\
\text { signifikan pada struktur modal. }\end{array}$ \\
\hline $\begin{array}{l}\text { Zulkarnain, } \\
(2020)\end{array}$ & $\begin{array}{l}\text { Pengaruh } \\
\text { Likuiditas dan } \\
\text { Profitabilitas } \\
\text { terhadap Struktur } \\
\text { Modal }\end{array}$ & $\begin{array}{l}\mathrm{X}_{1}: \text { Likuiditas } \\
\mathrm{X}_{2}: \text { Profitabilitas } \\
\mathrm{Y}: \text { Struktur Modal }\end{array}$ & $\begin{array}{l}\text { Likuiditas pengaruh negatif, } \\
\text { tidak signifikan terhadap } \\
\text { struktur modal. Profitabilitas } \\
\text { pengaruh positif dan tidak } \\
\begin{array}{l}\text { signifikan terhadap struktur } \\
\text { modal. }\end{array}\end{array}$ \\
\hline (Andika \& & Pengaruh & $\mathrm{X}_{1}$ : Profitabilitas & Profitabilitas tidak berpengaruh \\
\hline
\end{tabular}


Owner: Riset \& Jurnal Akuntansi

e-ISSN : 2548-9224 | p-ISSN : 2548-7507

Volume 6 Nomor 1, Januari 2022

DOI : https://doi.org/10.33395/owner.v6i1.589

\begin{tabular}{|c|c|c|c|}
\hline Sedana, 2019) & $\begin{array}{l}\text { Profitabilitas, } \\
\text { Struktur Aktiva, } \\
\text { Ukuran Perusahaan } \\
\text { terhadap Struktur } \\
\text { Modal }\end{array}$ & $\begin{array}{l}\mathrm{X}_{2}: \text { Struktur Aktiva } \\
\mathrm{X}_{3}: \text { Ukuran Perusahaan } \\
\text { Y: Struktur Modal }\end{array}$ & $\begin{array}{l}\text { terhadap struktur modal. } \\
\text { Struktur aktiva, ukuran } \\
\text { perusahaan berpengaruh positif } \\
\text { dan signifikan pada struktur } \\
\text { modal. }\end{array}$ \\
\hline $\begin{array}{l}\text { (Dzikriyah \& } \\
\text { Sulistyawati, } \\
\text { 2020) }\end{array}$ & $\begin{array}{l}\text { Pengaruh } \\
\text { Pertumbuhan } \\
\text { Penjualan, Struktur } \\
\text { Aktiva, Ukuran } \\
\text { Perusahaan, } \\
\text { Profitabilitas } \\
\text { Terhadap Struktur } \\
\text { Modal }\end{array}$ & $\begin{array}{l}\mathrm{X}_{1}: \text { Pertumbuhan } \\
\quad \text { Penjualan } \\
\mathrm{X}_{2}: \text { Struktur Aktiva } \\
\mathrm{X}_{3}: \text { Ukuran Perusahaan } \\
\mathrm{X}_{4}: \text { Profitabilitas } \\
\mathrm{Y}: \text { Struktur Modal }\end{array}$ & $\begin{array}{l}\text { Pertumbuhan penjualan, } \\
\text { struktur aktiva dan profitabilitas } \\
\text { berpengaruh terhadap struktur } \\
\text { modal, sementara ukuran } \\
\text { perusahaan tidak pengaruh pada } \\
\text { struktur modal. }\end{array}$ \\
\hline
\end{tabular}

Sumber: Data diolah (2021)

Struktur Modal

Struktur modal atau Debt to Equity Ratio (DER) adalah komposisi total hutang jangka pendek, hutang jangka panjang dibandingkan modal perusahaan berupa saham preferen dan saham biasa. Menurut (Septiani \& Suaryana, 2018) struktur modal yang maksimal akan membuatkan biaya modal paling rendah sehingga memaksimalkan nilai perusahaan.

Rasio DER yang memakai rumus:

Struktur modal $=$ Total Hutang

Total Ekuitas

\section{Profitabilitas}

Profitabilitas atau Return On Assets (ROA) diartikan sebagai kemampuan perusahaan memperoleh keuntungan selama kurun waktu yang ditentukan. Profitabilitas membuat suatu standar perhitungan mendapatkan laba. ROA yang menunjukkan komposisi dari laba bersih atas jumlah aset yang menggunakan rasio:

Profitabilitas $=\frac{\text { Laba Bersih }}{\text { Total Aset }}$

\section{Pertumbuhan Penjualan}

Pertumbuhan penjualan atau growth sales atau pertumbuhan pendapatan merupakan jumlah penjualan/pendapatan tahun sekarang (periode sekarang) dikurangi tahun (periode sebelumnya) dibagikan dengan jumlah penjualan tahun (periode sebelumnya).

Rumusnya menggunakan rasio dari:

Pertumbuhan penjualan $($ growth sales $)=\underline{\text { Total Penjualan }- \text { Total Penjualan }} \underline{\underline{\mathrm{t}}-1}$

Total Penjualan ${ }_{t-1}$

\section{Likuiditas}

Likuiditas atau Current Ratio (CR) merupakan kemampuan perusahaan untuk melunasi jumlah hutang jangka pendek, yang jangka waktu kurang satu tahun. Adapun likuiditas antara lain current ratio, cash ratio, quick ratio, net working capital to total assets ratio (Lasut, Rate, \& Raintung, 2018). Rasio likuiditas menunjukkan kemampuan perusahaan dalam memenuhi utang jangka pendek dengan aset lancar yang perusahaan miliki. Rasio diukur menggunakan rumus:

Likuiditas $=\frac{\text { Aset Lancar }}{\text { Utang Lancar }}$




\section{Ukuran Perusahaan}

Ukuran perusahaan merupakan media dalam memperkirakan ukuran keadaan perusahaan dengan aturan berlaku. Ukuran perusahaan dinilai dengan menggunakan proxi total aset perusahaan.

Skala rasio dihitung memakai rumus: Ukuran perusahaan $($ Size $)=\ln ($ Total Asset $)$

\section{Pengaruh Profitabilitas Terhadap Struktur Modal}

Perusahaan yang berprofitabilitas tinggi mempunyai dana internal cukup maka perusahaan dapat mempergunakan dana internal lebih dahulu. Laba yang semakin tinggi dicapai perusahaan, akan dapat mengurangi struktur modal perusahaan bersumber dari hutang. Tingginya tingkat keuntungan perusahaan cendrung akan memakai hutang sedikit disebabkan adanya profit besar yang boleh dipakai untuk sumber dana (Tijow, Sabijono, \& Tirayoh, 2018). Pendapat (Hidayat, Nurlaela, \& Samrotun, 2021) sejalan penelitian ini dan penelitian yang diteliti oleh (Effendi \& Nugraha, 2018) juga profitabilitas pengaruh negatif tidak signifikan terhadap struktur modal. Hasil yang diteliti oleh (Septiani \& Suaryana, 2018) mendukung bahwa profitabilitas berpengaruh negatif, tidak signifikan terhadap struktur modal. Berdasarkan teori dan hasil penelitian terdahulu, sehingga hipotesis dalam penelitian ini:

H1 : Profitabilitas memiliki pengaruh negatif tidak signifikan terhadap struktur modal.

\section{Pengaruh Pertumbuhan Penjualan Terhadap Struktur Modal}

Tingginya pertumbuhan penjualan cendrung diimbangi penambahan aset yang diperlukan dalam pengadaan persediaan produk. Jika perusahaan mempunyai pertumbuhan penjualan besar akan membutuhkan hutang lebih banyak sehingga pertumbuhan penjualan dapat berpengaruh negatif terhadap struktur modal (Dewiningrat \& Mustanda, 2018). Penelitian yang telah diteliti oleh (Meilyani, Suci, \& Cipta, 2019) pertumbuhan penjualan berpengaruh negatif dan tidak signifikan terhadap struktur modal.

$\mathrm{H} 2$ : Pertumbuhan penjualan berpengaruh negatif, tidak signifikan terhadap struktur modal.

\section{Pengaruh Likuiditas Terhadap Struktur Modal}

Perusahaan jika mempunyai current ratio besar umumnya selalu dapat melunasi kewajibannya sesuai dengan waktu yang telah ditentukan. Perusahaan yang mampu mencukupi kewajibannya secara tepat waktu menunjukkan perusahaan bisa menurunkan risiko maka akan membuat ketertarikan para investor untuk menanamkan modalnya ataupun kreditur memberi pinjaman pada perusahaan. Hasil penelitian dilakukan oleh (Nabayu, Marbun, Ginting, Sebayang, \& Sipahutar, 2020) likuiditas berpengaruh positif dan signifikan terhadap struktur modal.

H3 : Likuiditas pengaruh positif dan signifikan terhadap struktur modal.

\section{Pengaruh Ukuran Perusahaan Terhadap Struktur Modal}

Ukuran perusahaan adalah gambaran besarnya jumlah aset yang ada di perusahaan (Ivanka, Nurlaela, \& Suhendro, 2018). Hasil uji penelitian (Septiani \& Suaryana, 2018) ukuran perusahaan berpengaruh positif signifikan terhadap struktur modal. Maka ditarik hipotesis:

H4 : Ukuran perusahaan berpengaruh positif, signifikan terhadap struktur modal.

\section{Kerangka Pemikiran}

Kerangka pemikiran teoritis dapat digambarkan sebagai berikut: 


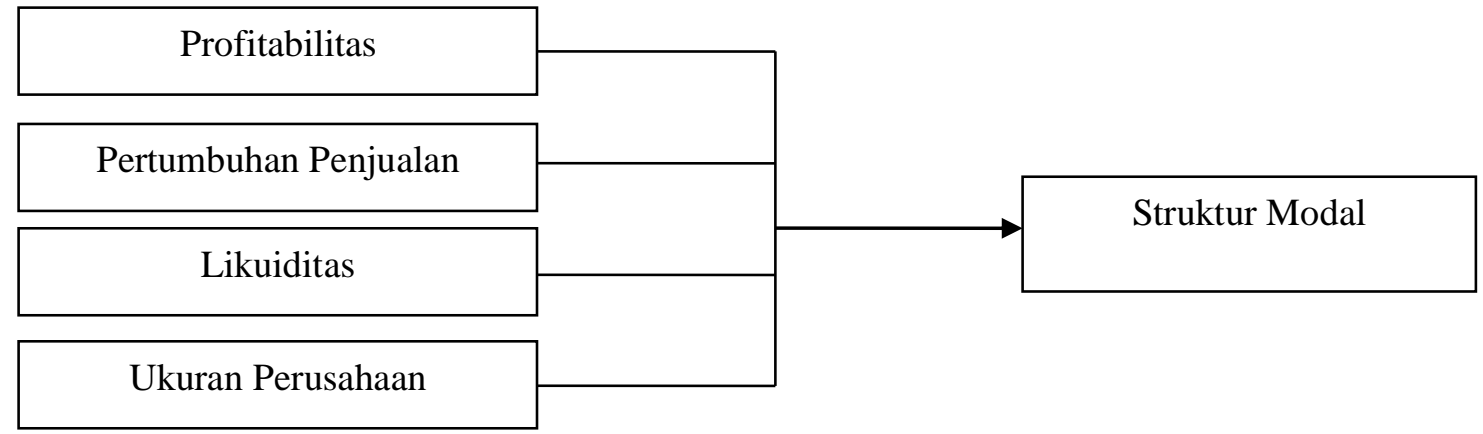

Gambar Model Pemikiran Penelitian

\section{Jenis Penelitian}

METODE

Penelitian ini merupakan suatu bentuk analisis kausal. Analisis kausal bermaksud meyakinkan terdapat bukti korelasi antara asal mula maupun akhir pengaruh terhadap variabel yang hendak diteliti. Penelitian kausal yang akan diteliti menjelaskan ROA, pertumbuhan penjualan, likuiditas, ukuran perusahaan dampaknya terhadap struktur modal pada perusahaan makanan dan minuman go public dengan cara menganalisa bukti untuk melaksanakan uji hipotesis.

\section{Analisa Data}

Variabel bebas (independen) yang akan diteliti dalam penelitian ini adalah pengaruh profitabilitas (ROA), pertumbuhan penjualan (sales growth), likuiditas (current ratio), dan ukuran perusahaan (size company). Sedangkan variabel terikat (dependen) diwakili oleh struktur modal (capital structure). Metode pengumpulan dan pemilihan data dengan menggunakan teknik pengumpulan data.

\section{Sumber Data}

Sumber data diperoleh dari BEI yang memakai annual report atau laporan tahunan yang didapat melalui www.idx.co.id. Data sekunder berbentuk pooled data artinya paduan cross section dengan time series.

\section{Populasi Penelitian}

Populasi merupakan gabungan manusia, objektivitas maupun seluruh kegiatan perihal dalam mempunyai pegangan spesifik yang ditetapkan. Pendapat (Sugiyono, 2017) populasi merupakan kawasan generalisasi mencakup subjek dan objek berkompeten maupun ciri khas spesifik diatur oleh peneliti agar dapat diteliti serta dibuat kesimpulan. Maka populasi selain manusia, termasuk objektivitas yang ada disekitarnya. Populasi yang akan diteliti ini merupakan seluruh perusahaan manufaktur sektor makanan dan minuman yang menggunakan waktu mulai 2017 sampai dengan serta terdaftar dalam BEI dengan jumlah populasinya 27 industri.

\section{Sampel Penelitian}

Sampel merupakan segmen kumpulan dari populasi yang hendak diteliti dapat untuk menggantikan suatu populasi penelitian. Metode pemilihan sampel dengan cara memanfaatkan metode sampel jenuh sebagai teknik memilih model sampel. Teknik tersebut bertujuan agar banyaknya populasi relatif berkurang, akan tetapi tujuannya supaya penelitian yang mengunakan generalisasi dapat menurunkan kesalahan seminimalnya. Sampel jenuh disebut juga sampling sensus. Adapun metode sampling sensus yang diterapkan penelitian ini yakni kriteria penentuan.

Menurut karakteristik penentuan perusahaan untuk penelitian, banyaknya populasi 27 maka menjadi berjumlah 14 perusahaan. Sistem menentukan pemilihan sampel di tabel 2 berikut. 
Tabel 2. Sampel dengan Kriteria Penentuan

\begin{tabular}{lc}
\hline \multicolumn{1}{c}{ Karakteristik } & Total \\
\hline Perusahaan sektor makanan dan minuman yang tercatat di BEI & 27 \\
\hline $\begin{array}{l}\text { Dikeluarkan karena perusahaan tidak mengungkapkan informasi struktur } \\
\text { modal di laporan tahunan periode tahun 2017-2019. }\end{array}$ & $(5)$ \\
\hline $\begin{array}{l}\text { Dikeluarkan karena perusahaan tidak mempublikasikan data likuiditas, } \\
\text { ROA, total aset secara lengkap. }\end{array}$ & $(8)$ \\
\hline Total Sampel & $\mathbf{1 4}$ \\
\hline Total Sampel Selama 3 Tahun & $\mathbf{4 2}$ \\
\hline
\end{tabular}

Sumber: Hasil Pengolahan Data (2021)

\section{HASIL}

Hasil penguraian analisa dan hasil uji hipotesis maupun deskritif supaya dapat memaparkan, mendeskripsikan variabel penelitian yang mencakup variabel bebas antara lain profitabilitas, pertumbuhan penjualan, likuiditas, ukuran perusahaan, sedangkan variabel terikatnya struktur modal. Nilai minimum, nilai maksimum, nilai rata-rata dan standar deviasi yang dihasilkan untuk setiap variabel dapat dijelaskan tabel 3 sebagai statistik deskriptif penelitian ini.

Tabel 3 Statistik Deskriptif

\begin{tabular}{|l|r|r|r|r|r|}
\hline & N & Minimum & Maximum & Mean & Std. Deviation \\
\hline Struktur Modal & 42 & .45 & 334.00 & 55.7238 & 70.37814 \\
Profitabilitas & 42 & .01 & 53.00 & 11.1012 & 11.80657 \\
Pertumbuhan Penjualan & 42 & -1.00 & .35 & .0327 & .24219 \\
Likuiditas & 42 & .49 & 863.78 & 177.2032 & 233.42398 \\
Ukuran Perusahaan & 42 & 10.36 & 27.40 & 16.3324 & 4.66860 \\
Valid N (listwise) & 42 & & & & \\
\hline
\end{tabular}

Sumber: Data hasil pengolahan SPSS 19

\section{Uji Asumsi Klasik}

\section{PEMBAHASAN}

Uji Asumsi klasik merupakan proses analisa supaya memperkirakan apakah dalam suatu model regresi linear Ordinary Least Square (OLS) mencapai syarat model regresi linear yang ditetapkan.

\section{Uji Normalitas}

Uji normalitas dilaksanakan dengan uji One-Sample-Kolmogorov-Smirnov agar mengetahui gambaran data model berdistribusi normal jika prob. asymp.sig (2-tailed) lebih besar dari 0.05. Nilai penelitian ini 0,463 sehingga dapat dibuktikan semua variabel memenuhi normalitas.

Tabel 4 Uji Kolmogorof Smirnov

\begin{tabular}{|c|c|c|}
\hline & & Unstandardized Residual \\
\hline \multicolumn{2}{|l|}{$\mathrm{N}$} & 42 \\
\hline Normal Parameters ${ }^{\mathrm{a}, \mathrm{b}}$ & Mean & .0000000 \\
\hline & Std. Deviation & 61.07712323 \\
\hline
\end{tabular}




\begin{tabular}{|ll|r|} 
& & \\
& & .131 \\
& Post Extreme Differences & Absolute \\
& Negative & .131 \\
Kolmogorov-Smirnov Z & & -.108 \\
Asymp. Sig. (2-tailed) & & .851 \\
\hline
\end{tabular}

a. Test distribution is Normal.

b. Calculated from data.

Sumber: Hasil olah SPSS 19

\section{Uji Multikolinearitas}

Uji multikolinieritas agar dapat membuktikan terdapat kemiripan antar variabel independen. Bila korelasi ditemui maka terjadi multikolinearitas yaitu dengan nilai tolerance $<0,10$ diperoleh nilai VIF $>10$. Uji multikolinieritas penelitian ini hasilnya bebas tidak mengalami multikolinearitas.

Tabel 5 Uji Multikolonieritas Coefficients $^{\mathrm{a}}$

\begin{tabular}{|c|c|c|c|c|c|c|c|}
\hline \multirow[b]{2}{*}{ Model } & \multicolumn{2}{|c|}{$\begin{array}{c}\text { Unstandardized } \\
\text { Coefficients }\end{array}$} & \multirow{2}{*}{$\begin{array}{c}\text { Standardized Coefficients } \\
\text { Beta }\end{array}$} & \multirow[b]{2}{*}{$\mathrm{t}$} & \multirow[b]{2}{*}{ Sig. } & \multicolumn{2}{|c|}{ Collinearity Statistics } \\
\hline & $\mathrm{B}$ & Std. Error & & & & Tolerance & VIF \\
\hline $\begin{array}{ll}1 & \text { (Constant) }\end{array}$ & -40.954 & 45.001 & & -.910 & .369 & & \\
\hline Profitabilitas & 2.054 & .930 & .345 & 2.208 & .034 & .836 & 1.197 \\
\hline Pertumbuhan Penjualan & -61.605 & 43.589 & -.212 & -1.413 & .166 & .905 & 1.105 \\
\hline Likuiditas & -.044 & .046 & -.145 & -.947 & .350 & .863 & 1.159 \\
\hline Ukuran Perusahaan & 5.122 & 2.370 & .340 & 2.161 & .037 & .823 & 1.215 \\
\hline
\end{tabular}

a. Dependent Variable: Struktur Modal

Sumber: Data hasil pengolahan SPSS 19

\section{Uji Heteroskedastisitas}

Uji heteroskedastisitas bermanfaat untuk mengetahui terdapat heterokedastisitas atau disebut sebagai homokesdastisitas maupun tidak adanya penyimpangan asumsi klasik heteroskedastisitas. Penelitian ini menganalisis terjadi tidaknya heteroskedastisitas dengan uji Glejser yang dapat menguji model regresi tidak adanya heteroskedastisitas. Pengujian heteroskedastisitas yang diperoleh ada pada nilai probabilitas signifikansi penelitian yaitu profitabilitas sebesar 0,317 pertumbuhan penjualan hasilnya 0,880 dan CR hasilnya 0,716 serta ukuran perusahaan sebesar 0,138 yang berarti tidak terjadi heteroskedastisitas.

Tabel 6 Uji Heteroskedastisitas

Coefficients $^{\mathrm{a}}$

\begin{tabular}{|c|c|c|c|c|c|c|c|c|}
\hline \multirow{2}{*}{\multicolumn{2}{|c|}{ Model }} & \multicolumn{2}{|c|}{$\begin{array}{c}\text { Unstandardized } \\
\text { Coefficients }\end{array}$} & \multirow{2}{*}{$\begin{array}{c}\begin{array}{c}\text { Standardized } \\
\text { Coefficients }\end{array} \\
\text { Beta }\end{array}$} & \multirow[b]{2}{*}{$\mathrm{t}$} & \multirow[b]{2}{*}{ Sig. } & \multicolumn{2}{|c|}{ Collinearity Statistics } \\
\hline & & $\mathrm{B}$ & Std. Error & & & & Tolerance & VIF \\
\hline \multirow[t]{5}{*}{1} & (Constant) & 10.988 & 30.341 & & .362 & .719 & & \\
\hline & Profitabilitas & -.637 & .627 & -.170 & -1.015 & .317 & .836 & 1.197 \\
\hline & Pertumbuhan Penjualan & 4.469 & 29.389 & .024 & .152 & .880 & .905 & 1.105 \\
\hline & Likuiditas & -.011 & .031 & -.060 & -.367 & .716 & .863 & 1.159 \\
\hline & Ukuran Perusahaan & 2.424 & 1.598 & .256 & 1.517 & .138 & .823 & 1.215 \\
\hline
\end{tabular}

a. Dependent Variable: RES2

Sumber: Hasil olah SPSS 19 


\section{Uji Autokorelasi}

Uji autokorelasi merupakan uji yang menganalisa secara statistik agar mendapati apabila terjadi korelasi antara kesalahan pengganggu pada periode $t$ dengan kesalahan waktu t sebelumnya. Untuk melaksanakan uji autokorelasi dalam penelitian ini berdasarkan uji durbin watson supaya mengetahui hubungan setiap variabel yang memakai model regresi yakni perubahan waktu. Hasil uji diperoleh nilai durbin watson Test pada model regresi sebesar $1.282>0,05$ tidak terjadi autokorelasi serta mencukupi ketentuan durbin watsonnya.

Tabel 7 Uji Autokorelasi Model Summary ${ }^{\mathrm{b}}$

\begin{tabular}{|l|r|r|r|r|r|}
\hline Model & $\mathrm{R}$ & R Square & $\begin{array}{c}\text { Adjusted R } \\
\text { Square }\end{array}$ & $\begin{array}{c}\text { Std. Error of the } \\
\text { Estimate }\end{array}$ & Durbin-Watson \\
\hline 1 & $.497^{\mathrm{a}}$ & .247 & .165 & 64.29388 & 1.282 \\
\hline
\end{tabular}

a. Predictors: (Constant), Ukuran Perusahaan, CR, Pertumbuhan Penjualan, ROA

b. Dependent Variable: DER

Sumber: Data hasil pengolahan SPSS 19

\section{Uji Hipotesis}

Penelitian ini menggunakan uji hipotesis dengan cara melakukan menguji $\mathrm{F}$ atau sering disebut uji anova maupun uji serentak sementara dalam melakukan pengujian $\mathrm{t}$ sebagai media menguji makna keberadaan koefisien regresi dengan taraf signifikansi $5 \%$.

\section{Uji F}

Uji F sebagai uji untuk mengetahui signifikansi atau tidaknya variabel independen berpengaruh pada variabel dependen secara bersama-sama ataupun simultan. Jika probabilitas uji serentak menunjukkan kurang dari 0,05 artinya secara serentak variabel independen dapat mempengaruhi variabel dependen.

Tabel 8 Uji F

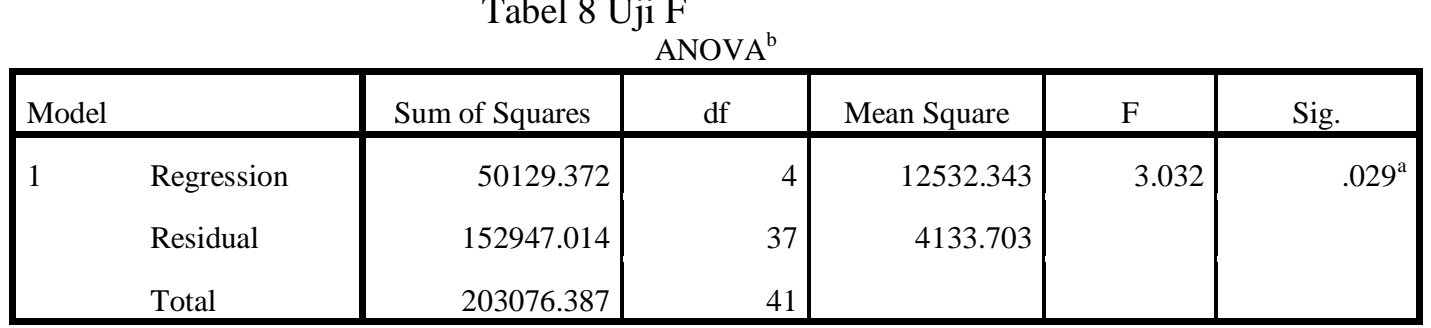

a. Predictors: (Constant), Ukuran Perusahaan, Likuiditas, Pertumbuhan Penjualan, Profitabilitas

b. Dependent Variable: Struktur Modal

Sumber: Hasil olah data SPSS 19

\section{Uji t}

Dilaksanakannya uji t sebagai alat uji statistik untuk dapat mengetahui dengan sistem parsial bukti nilai variabel bebas pada variabel terikat.

Tabel 9 Uji t

Coefficients $^{\mathrm{a}}$

\begin{tabular}{|c|c|c|c|c|c|}
\hline \multirow[b]{2}{*}{ Model } & \multicolumn{2}{|c|}{ Unstandardized Coefficients } & $\begin{array}{l}\text { Standardized } \\
\text { Coefficients }\end{array}$ & \multirow[b]{2}{*}{$\mathrm{t}$} & \multirow[b]{2}{*}{ Sig. } \\
\hline & $\mathrm{B}$ & Std. Error & Beta & & \\
\hline $1 \quad$ (Constant) & -40.954 & 45.001 & & -.910 & .369 \\
\hline
\end{tabular}


Owner: Riset \& Jurnal Akuntansi

e-ISSN : 2548-9224 | p-ISSN : 2548-7507

Volume 6 Nomor 1, Januari 2022

DOI : https://doi.org/10.33395/owner.v6i1.589

\begin{tabular}{|l|r|r|r|r|r|}
\hline Profitabilitas & 2.054 & .930 & .345 & 2.208 & .034 \\
Pertumbuhan Penjualan & -61.605 & 43.589 & -.212 & -1.413 & .166 \\
Likuiditas & -.044 & .046 & -.145 & -.947 & .350 \\
Ukuran Perusahaan & 5.122 & 2.370 & .340 & 2.161 & .037 \\
\hline
\end{tabular}

a. Dependent Variable: Struktur Modal

Sumber: Hasil olah SPSS 19

Menurut nilai uji statistik t ditentukan rumus persamaan regresi

DER $=-40.954+2.054$ ROA - 61.605 Pertumbuhan Penjualan - 0.044 CR + 5.122 SIZE

Pengujian hipotesis memberikan bukti dengan hasilnya profitabilitas memiliki pengaruh positif bersignifikan disebabkan prob. sig dibawah 0,05. Profitabilitas dapat membuat kenaikan struktur modal. Uji hipotesis yang diperoleh sejalan hasil dari (Zulkarnain, 2020). Penelitian ini menunjukkan bahwa profitabilitas berpengaruh positif dan signifikan pada DER.

Uji hipotesis menunjukan bahwa pertumbuhan penjualan dapat mempengaruhi negatif tidak signifikan karena probabilitas diperoleh diatas 0,05. Terbukti mendukung (Meilyani et al., 2019) berpendapat pertumbuhan penjualan pengaruhnya negatif tidak signifikan pada DER.

Pengujian menjelaskan likuiditas memiliki pengaruh negatif serta tidak signifikan pada struktur modal. Hasil ini sesuai dengan hipotesis tiga. Pengujian mendukung (Lilia et al., 2020), (Zulkarnain, 2020). Hasil penelitian (Komariah \& Nurulrahmatiah, 2020) dan (Effendi \& Nugraha, 2018) juga menyatakan likuiditas pengaruhnya negatif tidak signifikan pada DER.

Uji hipotesis menunjukan ukuran perusahaan memiliki pengaruh positif bersignifikan karena probabilitas sig lebih kecil dari 0,05. Pengujian hipotesis terbukti mendukung yang telah diteliti (Lilia et al., 2020) maupun (Pramana \& Darmayanti, 2020). Industri yang berukuran besar dengan jumlah aset banyak tidak mengalami kesulitan memperoleh pinjaman untuk penambahan modal dengan menjadikan aset perusahaan sebagai jaminan. Apabila ukuran perusahaan manufaktur sub makanan dan minuman bertambah besar dapat meningkatkan dana eksternal terutama keperluan utang yang hendak dipergunakan, maka akan mampu meningkatkan struktur modal. Teori ini sesuai dengan penelitian dari (Andika \& Sedana, 2019) dan penelitian oleh (Septiani \& Suaryana, 2018). Hasil yang sama juga ditemukan oleh (Lasut et al., 2018) size berpengaruh positif signifikan pada DER.

\section{Koefisien Determinasi}

Uji koefisien korelasi bertujuan mengetahui kemampuan semua variabel dependen untuk menjelaskan bukti hubungannya bersama variabel independen (Ghozali, 2016). Pengujian adjusted $R^{2}$ bermanfaat dalam mengukur ketentuan jumlah proporsi persen untuk variabel terikat dapat dijelaskan variabel bebas. Uji adjusted $R^{2}$ membuktikan hasil koefisien determinasi yaitu senilai 0,165 berarti $16,5 \%$ struktur modal mampu dijelaskan ROA, pertumbuhan penjualan, likuiditas dan ukuran perusahaan, sementara $83.5 \%$ dapat dipengaruhi variabel yang tidak ada dalam penelitian.

Tabel 10 Hasil Uji Koefisien Determinasi Model Summary ${ }^{\mathrm{b}}$

\begin{tabular}{|l|r|r|r|r|}
\hline Model & \multicolumn{1}{|c|}{ R } & \multicolumn{1}{|c|}{ R Square } & Adjusted R Square & \multicolumn{1}{|c|}{ Std. Error of the Estimate } \\
\hline 1 & $.497^{\mathrm{a}}$ & .247 & .165 & 64.29388 \\
\hline
\end{tabular}

a. Predictors: (Constant), Ukuran Perusahaan, Likuiditas, Pertumbuhan Penjualan, Profitabilitas

b. Dependent Variable: Struktur Modal

Sumber: Data hasil pengolahan SPSS 19 


\section{KESIMPULAN}

Hasil pengujian yang telah diperoleh menurut penguraian analisis mengenai pengaruh ROA, pertumbuhan penjualan, likuiditas, ukuran perusahaan terhadap struktur modal perusahaan manufaktur sektor makanan dan minuman tercatat BEI pada periode 2017-2019 dengan jumlah sampel sebanyak 14 perusahaan, dapat ditarik kesimpulan bahwa ROA berpengaruh positif dan signifikan terhadap struktur modal perusahaan, sedangkan pertumbuhan penjualan berpengaruh negatif dan tidak signifikan terhadap struktur modal perusahaan. Pada variabel likuiditas hasilnya berpengaruh negatif dan tidak signifikan terhadap struktur modal sedangkan hasil pengujian pada variabel ukuran perusahaan memiliki pengaruh positif dan signifikan terhadap struktur modal perusahaan. Hasil penelitian profitabilitas, pertumbuhan penjualan, likuiditas dan ukuran perusahaan yang dilakukan serentak berpengaruh positif dan signifikan terhadap struktur modal.

\section{REFERENSI}

Andika, I. K. R., \& Sedana, I. B. P. (2019). PENGARUH PROFITABILITAS, STRUKTUR AKTIVA, DAN UKURAN PERUSAHAAN TERHADAP STRUKTUR MODAL. E-Jurnal Manajemen, 8(9), 5803-5824. https://doi.org/DOI: https://doi.org/10.24843/EJMUNUD.2019.v08.i09.p22 ISSN

Dewiningrat, A. I., \& Mustanda, I. K. (2018). PENGARUH LIKUIDITAS, PROFITABILITAS, PERTUMBUHAN PENJUALAN, DAN STRUKTUR ASET TERHADAP STRUKTUR MODAL. E-Jurnal Manajemen Unud, 7, 18-31. https://doi.org/10.24843/EJMUNUD.2018.v7.i07.p2

Dzikriyah, \& Sulistyawati, A. I. (2020). Pengaruh Pertumbuhan Penjualan, Struktur Aktiva, Ukuran Perusahaan Dan Profitabilitas Terhadap Struktur Modal. Solusi, 18(3), 99-115. https://doi.org/10.26623/slsi.v18i3.2612

Effendi, M., \& Nugraha. (2018). Return on Assets, Likuiditas Dan Ukuran Perusahaan Terhadap Struktur Modal. Agregat, 2(1), 44-54. https://doi.org/10.22236/agregat

Farisa, N. A., \& Widati, L. W. (2017). ANALISA PROFITABILITAS, LIKUIDITAS, PERTUMBUHAN PENJUALAN, STRUKTUR AKTIVA DAN KEBIJAKAN DIVIDEN TERHADAP STRUKTUR MODAL. Prosiding Seminar Nasional Multi Disiplin \& Call for Papers UNISBANK Ke-3, (2011), 640-649.

Hidayat, O. E. M., Nurlaela, S., \& Samrotun, Y. C. (2021). Pengaruh current ratio, struktur aktiva dan return on asset terhadap struktur modal The influence of the current ratio, asset structure and return on assets to the capital structure. 17(2), 217-227.

Ivanka, F. J., Nurlaela, S., \& Suhendro. (2018). RESIKO BISNIS, PROFITABILITAS, LIKUIDITAS, UKURAN PERUSAHAAN DAN STRUKTUR MODAL PADA PERUSAHAAN SUB SEKTOR MAKANAN DAN MINUMAN. JAE: JURNAL AKUNTANSI DAN EKONOMI, 6, 103-112. https://doi.org/10.29407/jae.v6i1.14650

Kharizmatullah, Yuliani, \& Ghasarma, R. (2017). ANALISIS STRUKTUR MODAL PERUSAHAAN INDUSTRI MAKANAN DAN MINUMAN DI BURSA EFEK INDONESIA. In Ekspektra : Jurnal Bisnis dan Manajemen (Vol. 1). https://doi.org/http://dx.doi.org/10.25139/ekt.v0i0.135

Komariah, N., \& Nurulrahmatiah, N. (2020). PENGARUH STRUKTUR AKTIVA DAN LIKUIDITAS TERHADAP STRUKTUR MODAL. BALANCE : JURNAL AKUNTANSI DAN BISNIS, 5(2), 112 122. 
Lasut, S. J. D., Rate, P. V., \& Raintung, M. C. (2018). Pengaruh Ukuran Perusahaan, Profitabilitas, Dan Likuiditas Terhadap Struktur Modal Pada Perusahaan Otomotif Yang Terdaftar Di Bursa Efek Indonesia Periode 2012-2015. Jurnal EMBA: Jurnal Riset Ekonomi, Manajemen, Bisnis Dan Akuntansi, 6(1), 11-21. https://doi.org/10.35794/emba.v6i1.18705

Lilia, W., Situmeang, S. I. L., Verawaty, \& Hartanto, D. (2020). Pengaruh Profitabilitas, Likuiditas, Ukuran Perusahaan terhadap Struktur Modal Perusahaan Property dan Real Estate yang terdaftar di BEI. Owner (Riset Dan Jurnal Akuntansi), 4(2), 627. https://doi.org/10.33395/owner.v4i2.259

Meilyani, I. G. A. A., Suci, N. M., \& Cipta, W. (2019). PENGARUH RISIKO BISNIS, UKURAN PERUSAHAAN DAN PERTUMBUHAN PENJUALAN TERHADAP STRUKTUR MODAL PADA PERUSAHAAN PROPERTI DAN REAL ESTATE YANG TERDAFTAR DI BURSA EFEK INDONESIA. Jurnal Prospek, 1(2), 15-24.

Nabayu, Y. P., Marbun, N., Ginting, H. F., Sebayang, N. A., \& Sipahutar, T. T. U. (2020). Pengaruh profitabilitas, struktur aktiva, dan likuiditas terhadap struktur modal pada perusahaan makanan minuman yang terdaftar di Bursa Efek Indonesia pada tahun 2014-2017. Jurnal Paradigma Ekonomika, 15(2), 147-162. https://doi.org/10.22437/paradigma.v15i2.10316

Pramana, I. W. S., \& Darmayanti, N. P. A. (2020). Profitabilitas, Struktur Aktiva, Dan Ukuran Perusahaan Berpengaruh Terhadap Struktur Modal Perusahaan Otomotif. E-Jurnal Manajemen Universitas Udayana, 9(6), 2127. https://doi.org/10.24843/ejmunud.2020.v09.i06.p04

Septiani, N. P. N., \& Suaryana, I. G. N. A. (2018). Pengaruh Profitabilitas, Ukuran Perusahaan, Struktur Aset, Risiko Bisnis dan Likuiditas pada Struktur Modal. E-Jurnal Akuntansi, 22, 1682. https://doi.org/10.24843/eja.2018.v22.i03.p02

Tijow, A. P., Sabijono, H., \& Tirayoh, V. Z. (2018). PENGARUH STRUKTUR AKTIVA DAN PROFITABILITAS TERHADAP STRUKTUR MODAL PADA PERUSAHAAN SEKTOR INDUSTRI BARANG KONSUMSI YANG TERDAFTAR DI BURSA EFEK INDONESIA Anggelita. Jurnal Riset Akuntansi Going Concern, 13(3), 477-488.

Zulkarnain, M. (2020). Pengaruh likuiditas dan profitabilitas terhadap struktur modal. Forum Ekonomi, 22(1), 49-54. Retrieved from https://journal.feb.unmul.ac.id/index.php/FORUMEKONOMI/article/view/7005 